\title{
A NOTE ON THE HARDY-LITTLEWOOD INEQUALITIES FOR MULTILINEAR FORMS
}

\author{
Antonio Gomes Nunes
}

Abstract. The notion of entropy of the Hardy-Littlewood inequalities for multilinear forms was introduced and explored by Pellegrino and Teixeira in [14]. In this note, among other results, we introduce a related notion and obtain some new estimates.

Mathematics subject classification (2010): 46G25.

Keywords and phrases: Optimal constants, Hardy-Littlewood inequality.

\section{REFERENCES}

[1] N. Albuquerque, L. ReZende, Anisotropic Regularity Principle in sequence spaces and applications, to appear in Comm. Contemp. Math.

[2] N. Albuquerque, T. Nogueira, D. Núñez-Alarcón, D. Pellegrino, P. Rueda, Some applications of the Hölder inequality for mixed sums, Positivity 21 (2017), 1575-1592.

[3] G. Araújo, D. Pellegrino, Lower bounds for the constants of the Hardy-Littlewood inequalities, Linear Algebra Appl. 463 (2014), 10-15.

[4] G. Araújo, D. Pellegrino, D. D. P. Silva e Silva, On the upper bounds for the constants of the Hardy-Littlewood inequality, J. Funct. Anal. 267, 6 (2014), 1878-1888.

[5] F. BAYART, Multiple summing maps: Coordinatewise summability, inclusion theorems and p-Sidon sets, to appear in J. Funct. Anal, doi.org/10.1016/j.jfa.2017.08.013.

[6] H. F. Bohnenblust, E. Hille, On the absolute convergence of Dirichlet series, Ann. of Math. 32 (1931), 600-622.

[7] J. R. Campos, W. Cavalcante, V. V. Favaro, D. Pellegrino, D. Serrano-Rodriguez, Polynomial and multilinear Hardy-Littlewood inequalities: analytical and numerical approaches, Math. Ineq. Appl. 21 (2018), 329-344.

[8] W. Cavalcante, Some applications of the regularity principle in sequence spaces, Positivity, 22 (2018), 191-198. https://doi.org/10.1007/s11117-017-0506-9.

[9] W. CaValcante And D. NúÑeZ-Alarcón, Remarks on an inequality of Hardy and Littlewood, Quaest. Math. 39 (2016), 1101-1113.

[10] G. Hardy, J. E. LitTlewood, Bilinear forms bounded in space $[p, q]$, Quart. J. Math. 5 (1934), 241-254.

[11] M. Maia, T. Nogueira, D. Pellegrino, The Bohnenblust-Hille inequality for polynomials whose monomials have a uniformly bounded number of variables, Integral Equations Operator Theory 88, 1 (2017), 143-149.

[12] T. Nogueira, P. RUedA, Summability of multilinear forms on classical sequence spaces, Quaest. Math. 40 (2017), 803-809.

[13] D. Pellegrino, J. Santos, D. Serrano-Rodríguez, E. V. TeiXeira, A regularity principle in sequence spaces and applications, Bull. Sci. Math. 141, 8 (2017), 802-837.

[14] D. Pellegrino, E. V. Teixeira, Towards sharp Bohnenblust-Hille constants, Comm. Contemp. Math. 20, 3 (2018), 1750029, 33 pp. doi.org/10.1142/S0219199717500298.

[15] T. Praciano-Pereira, On bounded multilinear forms on a class of $l_{p}$ spaces, J. Math. Anal. Appl. 81, 2 (1981), 561-568. 